\title{
Environmental Impact Assessment of GHG Emissions Generated by Coal Life Cycle and Solutions for Reducing $\mathrm{CO}_{2}$
}

\author{
Cristian Dincă ${ }^{1}$, Călin-Cristian Cormoş ${ }^{2}$, Horia Necula ${ }^{1}$ \\ ${ }^{1}$ Power Plant Department, University Politehnica Bucharest, Bucharest, Romania; ${ }^{2}$ Facultatea de Chimieşi de Inginerie Chimică, \\ Universitatea Babeş-Bolyai, Cluj-Napoca, Romania. \\ Email: crisflor75@yahoo.com, cormos@chem.ubbcluj.ro,horia@energ.pub.ro
}

Received June $14^{\text {th }}, 2013$; revised July $12^{\text {th }}, 2013$; accepted August $9^{\text {th }}, 2013$

Copyright (C) 2013 Cristian Dincă et al. This is an open access article distributed under the Creative Commons Attribution License, which permits unrestricted use, distribution, and reproduction in any medium, provided the original work is properly cited.

\begin{abstract}
The objective of this paper consists of evaluating the coal life cycle and proposing technical solutions for reducing GHG emissions. After applying the life cycle assessment on the coal life cycle, it was noticed that the power engineering stage has a bigger environmental impact on different indicator impacts. In order to reduce the GHG emissions the $\mathrm{CO}_{2}$ chemical absorption process was integrated in the power plant based on the circulating fluidized bed combustion technology. Two cases were analyzed: super-critical and ultra-supra-critical parameters. For each case the environmental indicators (global warming potential, abiotic depletion potential, human toxicity potential, photochemical potential, acidification potential, eutrophisation potential) were evaluated in order to estimate the environmental effects on the coal life cycle with $\mathrm{CO}_{2}$ capture process. After the integration of the $\mathrm{CO}_{2}$ capture post-combustion process into the power plant, the GHG emissions decreased from $450,760 \mathrm{CO}_{2}$ equiv. tons to $75,937 \mathrm{CO}_{2}$ equiv. tons for super-critical parameters and from $438122 \mathrm{CO}_{2}$ equiv. tons to $73245 \mathrm{CO}_{2}$ equiv. tons for ultra-supra-critical parameters respectively. In order to increase the absorption capacity of the MEA solvent the $\mathrm{SO}_{2}$ emissions were reduced from flue gases and consequently the acidification potential was reduced too in both cases. On the contrary, the amount of fuel increased in order to maintain the functional unit as a result of the efficiency penalty of the $\mathrm{CO}_{2}$ capture integration in the power plant.
\end{abstract}

Keywords: $\mathrm{CO}_{2}$ Capture; Coal; LCA; Amines

\section{Introduction}

The coal is nowadays one of the main primary energies which the energy sector uses for covering the electricity demand. However, despite the fact that it is attracttive for the energy sector, the coal combustion poses some environmental issues. According to latest data, the reserve reported to production $(\mathrm{R} / \mathrm{P})$ ratios vary significantly [1]: for oil it is about 45.7 years, for natural gas 62.8 years and for coal 119 years. Coal is in the best position as it gives the longest energy independence, and its reserves are more uniformly spread, which makes the world market more stable and prices are not so volatile. The concerning aspects linked with coal usage in the energy sector are $\mathrm{CO}_{2}$ emissions. For example, for the generation of one MWh of electricity, the $\mathrm{CO}_{2}$ emission in the case of natural gas is about $350-400 \mathrm{~kg}$, and in the case of the coal is about $800-900 \mathrm{~kg}$ [2]. The continuation of coal usage for power generation is sustainable only if $\mathrm{CO}_{2}$ is captured and then safely stored for a long time.

The need to increase the security of primary energy sources and to reduce $\mathrm{CO}_{2}$ emissions, leads to the large scale utilization of renewable energy sources (solar, wind, tides, biomass etc.) at a large scale. In this context, the European Commission has set a target for the EU that until $2020,20 \%$ of the whole energy mix should be covered by renewable energy sources as well as that there should be a $20 \%$ cut of $\mathrm{CO}_{2}$ emissions compared with 1990 levels [3]. Furthermore, the European Union is prepared to cut $30 \%$ of $\mathrm{CO}_{2}$ emissions by 2020 if other developed countries proceed to similar cuts. Along this line, Romania has a significant potential of renewable energy sources, just to mention the ones related to this project proposal various biomass sorts (e.g. sawdust, agricultural wastes, etc.). Regarding the environmental 
protection and the mitigation of climate change, the reports of Intergovernmental Panel on Climate ChangeIPCC [4] established on scientific basis that the climate change and the rise of global temperature levels noticed over the past 50 years are linked with human activity and associated with greenhouse gas emissions (mainly $\mathrm{CO}_{2}$ ). According to IPCC statistics, the sectors that generate the highest $\mathrm{CO}_{2}$ emissions are: the power generation (21.3\%), the industrial sector $(16.8 \%)$ and the transport sector (14.0\%). These constantly increasing greenhouse gas emissions are responsible for an increase in temperatures, which is expected to continue over the coming decades to reach up to $+1.4^{\circ}$ to $+5.8^{\circ} \mathrm{C}$ globally by the year 2100 (compared with 1990 temperatures). Temperature increases are causing severe droughts in some parts of the world and extreme weather conditions. One main target related to the limitation of global warming is to take serious actions to limit the global average temperature increase to $2^{\circ} \mathrm{C}$ compared with preindustrial levels. Research shows that stabilizing the level of greenhouse gases at $450 \mathrm{ppm}$ would lead to a 1 in 2 chances to reach the target of $2^{\circ} \mathrm{C}$ compared with a 1 in 6 chance if levels reach $550 \mathrm{ppm}$ and a 1 in 16 chance if the level hits 650 $\mathrm{ppm}$. In terms of reducing greenhouse gas emissions this means that the global emissions must fall by almost $50 \%$ compared with 1990 levels by 2050, which implies a 60 to $80 \%$ reduction for developed countries [5].

In order to mitigate the climate change, a special attention is given to the reduction of $\mathrm{CO}_{2}$ emissions by means of capture and storage (CCS) techniques. When it comes to $\mathrm{CO}_{2}$ capture, there are several options: post-combustion capture, pre-combustion capture, oxy-combustion or different emerging new technologies which are very promising in terms of reducing $\mathrm{CO}_{2}$ capture penalties e.g. chemical looping, polymeric membranes, enzymatic systems etc. [6,7]. Some of the potential industries with significant $\mathrm{CO}_{2}$ reduction capabilities considering stationary sources are: power generation and some industrial sectors having large energy consumptions (e.g. cement, metallurgy, chemical, pulp and paper etc.).

Over the last period, several scientific papers have analyzed different power generation technologies based on coal using the life cycle assessment [8-19]. The scientific analyses focused on $\mathrm{CO}_{2}$ capture post and oxy combustion technology integration in the energy power plants [8,9]. Also, other authors have developed and adapted the life cycle assessment methodology by integrating CCS technology in the energy units $[10,11]$. Kather et al. and Husebye et al. studied the technical and economic effects of the capture, transport and storage technology integration in the pulverized coal combustion power plant $[12,13]$. In another paper the authors developed a database on the emissions generated in the power plant stage, and they determined the stripper performance in terms of energy [14]. In the same vein, in the paper of Jassim et al., the authors have created an absorber/stripper model [15]. Lawal et al. have elaborated a model based on $\mathrm{CO}_{2}$ capture integration in the coal fired power plant at a demonstrative scale [16].

However, these works are focused on assessing emissions of greenhouse gases in the stage of converting coal into electricity. Just a few scientific papers take into consideration all the coal life cycle stages but without tacking in consideration energy production using the circulating fluidized bed coal combustion technology. Therefore, this paper is intended to assess the environmental impact considering the coal life cycle by integrating the circulating fluidized bed combustion equipped with $\mathrm{CO}_{2}$ capture by chemical absorption unit.

In this paper we analyzed the coal life cycle energy with power generation in a circulating fluidized bed combustion technology. The inventory and the impact assessment were based on the life cycle analysis methodology and on the CML methodology proposed by the University of Leiden (Netherlands) [17]. In this analysis, we have identified all the greenhouse gases throughout the coal life cycle (extraction, treatment, transport and combustion stage) and we specified the contribution of every gas to the total $\mathrm{CO}_{2}$ equivalent.

\section{Material and Methods}

\subsection{Life Cycle Assessment Methodology}

In this paper we used the life cycle methodology in order to evaluate the GHG emissions generated by the entire coal life cycle. The life cycle assessment permits identifying and quantifying all the greenhouses gases generated throughout the entire coal life cycle. According to ISO, the LCA methodology consists in four steps: Goal and Scope, Life Cycle Inventory (LCI) analysis, Life Cycle Impact Assessment (LCIA) and Interpretation [17].

\subsection{Definition of Scope and Goal}

The objective of the paper consists in evaluating the greenhouses gases generated by the coal life cycle in the followings stages: coal extraction, coal treatment, coal transport and coal combustion for electricity generation. The environmental effects on the $\mathrm{CO}_{2}$ capture chemical absorption process integration in the power plant will be also evaluated.

The paper analyzed two cases concerning the electricity required by the processes before the combustion stage. Figure 1 presents the coal life cycle in the case when the energy required by every stage is provided by the coal life cycle. $M_{c b}^{1}, M_{c b}^{2}, M_{c b}^{3}$ represent the amount of fuel required by the energy unit in order to provide the electricity for the process. $M_{c b}^{e x}, M_{c b}^{t r}, M_{c b}^{t p}$ represent 
the amount of raw coal extracted, the amount before the treatment process and the amount of coal that is transported to the consumer.

The efficiency for every process (extraction, treatment and transport) is defined by: $\eta_{e x}, \eta_{t r}, \eta_{t p} . E_{t}$ is the annual electricity produced by the power plant.

Figure 2 shows the case when the energy required by each of the process above mentioned is generated by the national energy system.

The cases analyzed in this paper are divided in two groups: Case 1 refers to the coal life cycle without $\mathrm{CO}_{2}$ capture; Case 2 refers to the coal life cycle with $\mathrm{CO}_{2}$ capture process. In both cases the electricity required by the processes of the coal life cycle (extracting, treatment, transport stage) is provided by the national energy system. The cases are:

- Case 1: Coal life cycle without $\mathrm{CO}_{2}$ capture section;

- Case 2: Coal life cycle with $\mathrm{CO}_{2}$ capture section.

In the second case, the energy generated by the national energy system takes into account the primary energy in the mix of national energy. So, the pollutant emission $\left(e_{p}\right)$ generated by the energy consumed by every process is determined with the relation 1 .

$$
e_{p}=\sum_{i=1}^{n} e_{p}^{i}
$$

where:

$e_{p}^{i}$ - pollutant emission according to the primary energy used, $i$, in $\mathrm{g} / \mathrm{kWh}$.

The energy needed for the upstream stages of the energy production stage comes from the national power grid and it correspondsto the mix: coal-38\%; hydro$27 \%$; nuclear $-20 \%$; natural gas $-13 \%$ petroleum $-2 \%$ [18].
Figure 3 presents the processes included in the coal life cycle. The power plant is equipped with a $\mathrm{CO}_{2}$ capture post-combustion system. For the amine regeneration, a steam flow is extracted from the steam turbine, $(\mathrm{S})$.

Legend:

$E_{e}$ - the electricity consumed in the extraction process, in MWh;

$E_{t r}$ - the electricity consumed in the treatment process, in MWh;

$E_{t p}$ - the electricity consumed in the transport process, in MWh.

\subsection{Functional Unit}

In this analysis, in order to compare the coal life cycle with and without the $\mathrm{CO}_{2}$ capture section we have proposed the functional unit: the annual electricity required for a consumer. The electricity required by the consumer $\left(E_{c}\right)$ from the residential and tertiary sector is:

$$
E_{c}=E_{p}^{y} \cdot N_{y}
$$

where:

$E_{p}^{y}$-represents the annual electricity required by a person, in MWh/year/pers;

$N_{y}$ - the number of persons;

The amount of the fuel necessary to be produced by the electricity unit $\left(E_{t}\right)$ is:

$$
E_{t}=\frac{E_{c}}{\eta_{e}}
$$

$\eta_{e}$-represents the efficiency of the electricity distribution process (taking into account the electricity loss), in $\%$.

Table 1 presents all the specific emissions (in $\mathrm{gr} / \mathrm{kg}$ fuel) generated by the coal life cycle for extraction,

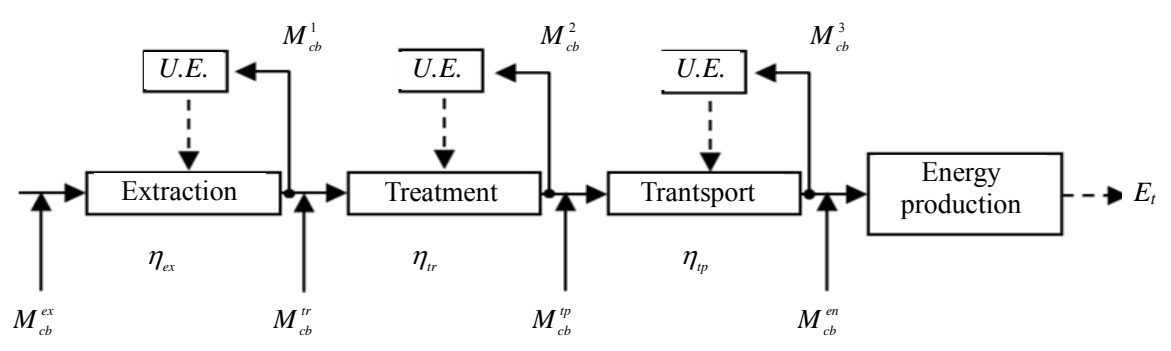

Figure 1. Coal life cycle-Case 1.

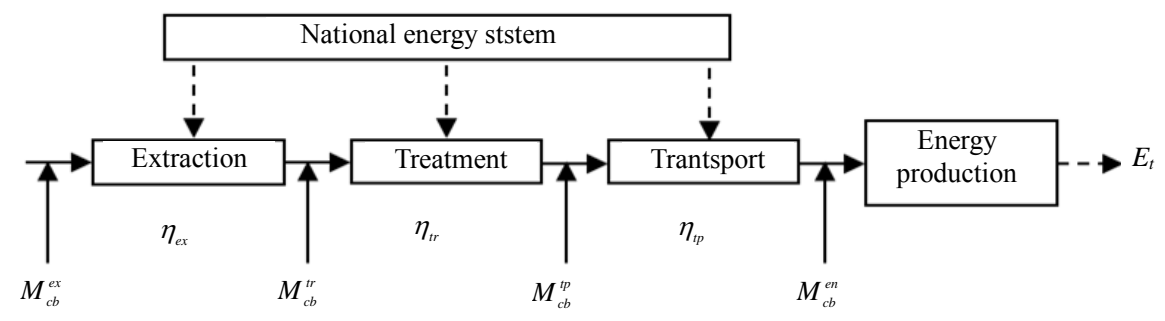

Figure 2. Coal life cycle-Case 2. 


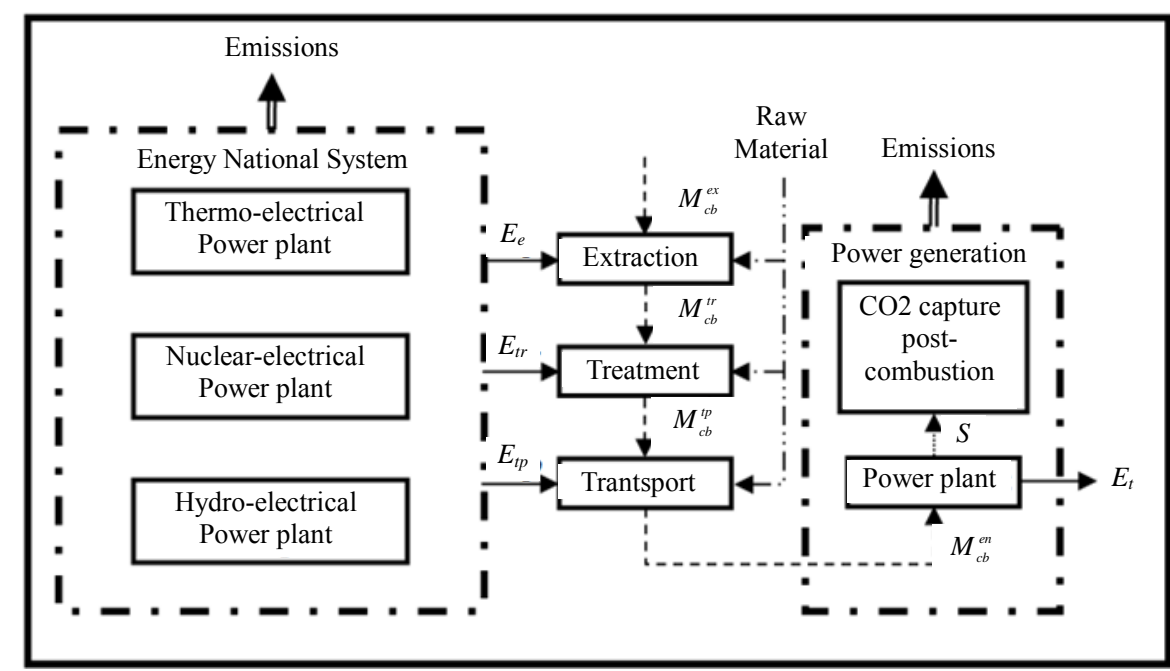

Figure 3. The boundaries of the studied system.

Table 1. The emissions generated by the each stage of the coal life cycle, in $\mathrm{gr} / \mathrm{kg}$.

\begin{tabular}{ccccc}
\hline Emission & Extraction & Treatment & Transport & Combustion \\
\hline $\mathrm{NH}_{3}$ & 0.0494 & 0.0245 & $2.21 \times 10^{-7}$ & 0.000121 \\
$\mathrm{CO}_{2}$ & 3.643 & 3.74 & 0.039 & 1103.187 \\
$\mathrm{CO}$ & 0.00381 & 0.00322 & 0.00322 & 0.1737 \\
$\mathrm{HCl}$ & $1.31 \times 10^{-9}$ & $3.05 \times 10^{-9}$ & $3.1 \times 10^{-10}$ & $4.07 \times 10^{-5}$ \\
$\mathrm{HF}$ & $2.43 \times 10^{-9}$ & $5.26 \times 10^{-9}$ & $1.64 \times 10^{-11}$ & $1.96 \times 10^{-6}$ \\
$\mathrm{H} \mathrm{S}^{-9}$ & $1.03 \times 10^{-9}$ & $1.12 \times 10^{-9}$ & $6.87 \times 10^{-13}$ & $1.7 \times 10^{-7}$ \\
$\mathrm{CH}$ & 0.6391 & 0.00738 & $2.04 \times 10^{-6}$ & $9.89 \times 10^{-9}$ \\
$\mathrm{NO}_{\mathrm{x}}$ & 0.0191 & 0.0173 & 0.000413 & 0.00943 \\
$\mathrm{~N}_{2} \mathrm{O}$ & 0.000316 & 0.000466 & $5.5 \times 10^{-7}$ & 3.4639 \\
$\mathrm{Praf}$ & 0.00789 & 0.00153 & $4.12 \times 10^{-5}$ & 0.00353 \\
$\mathrm{SO}_{2}$ & 0.0412 & 0.0112 & $2.13 \times 10^{-4}$ & 10.198 \\
$\mathrm{C}_{6} \mathrm{H}_{6}$ & - & - & - & 7.2598 \\
\hline
\end{tabular}

treatment, transport and combustion stage. In order to determine the emissions generated in the energy process for producing the annual electricity $\left(P_{i k \_r c}\right)$, relation 4 is used. All the emissions collected are determined according to the functional unit. As a result, the emissions given in Table $1\left(P_{i k}\right)$ are corrected with the fuel mass $\left(M_{\text {comb }}^{i}\right)$ corresponding to the analyzed stage.

$$
P_{i k_{-} \text {rec }}=P_{i k} \cdot M_{\text {comb }}^{i}
$$

\subsection{Coal Life Cycle Impact Assessment}

The methodology CML was used for quantifying the GHG emissions collected in the inventory analysis. The impact analysis is a methodology where the potential impact of the resource requirements and emissions is classified, characterized and evaluated. The impact assessment includes three steps:

- Classification: relates the emissions to the relevant impact categories;

- Characterization: quantifies the contribution of emissions to the relevant impact categories (e.g., convert $\mathrm{NO}_{\mathrm{x}}$ to $\mathrm{SO}_{2}$ equivalents);

- Evaluation: ranks the relevant impact categories.

Table 2 shows all environmental indicators for energy solutions evaluation.

Figures 4-6 show the climate change impact evaluation for different coal life cycles which takes into account the extraction, treatment, transport and energy generation stages: pulverized coal (sub-critical, supra-critical and ultra-supra-critical parameters); circulating fluidized bed 
Table 2. The environmental indicators.

\begin{tabular}{cccc}
\hline Class impact & Emissions participants & Reference pollutant & Impact scale \\
\hline Global warming potential (GWP) & $\mathrm{CO}_{2}, \mathrm{CH}_{4}, \mathrm{~N}_{2} \mathrm{O}$ & $\mathrm{CO}_{2}$-equiv. & Global \\
Acidification potential (AP) & $\mathrm{SO}_{\mathrm{x}}, \mathrm{NO}_{\mathrm{x}}, \mathrm{HCl}, \mathrm{HF}, \mathrm{NH}_{3}$ & $\mathrm{SO}_{2}$-equiv. & Regional, local \\
Eutrophication potential (EP) & $\mathrm{NO}, \mathrm{NO}_{2}, \mathrm{NH}_{3}, \mathrm{PO}_{4}^{3-}$ & $\mathrm{PO}_{4}^{3-}$-equiv. & Local \\
Photo-oxidant formation potential (POCP) & $\mathrm{NMHC}$ & $\mathrm{C}_{2} \mathrm{H}_{6}$-equiv. & Local \\
Human toxicity potential (HTP) & Dust, $\mathrm{Hg}, \mathrm{H}_{2} \mathrm{~S}, \mathrm{NO}_{2}, \mathrm{NH}_{3}, \mathrm{SO}_{2}$ & $1,4 \mathrm{DCB}$ equiv. & Global, Regional, Local \\
Abiotic resources depletion potential (ADP) & Coal & Antimoniu eqiv. & Global, Regional, Local \\
\hline
\end{tabular}

Comparative assessment of different coal life cycle according to climate change $\left(\mathrm{CO}_{2}\right.$ eqiuiv. tons)

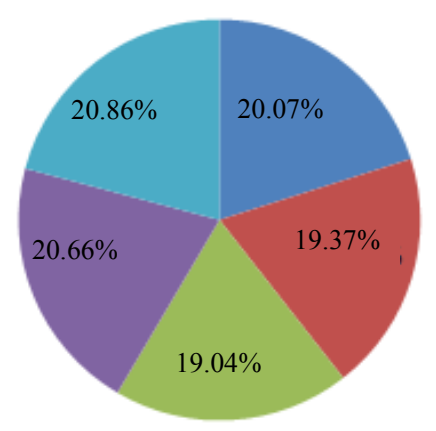

mAP_Sc $\square$ AP_SC $\square$ AP_USC $\square$ ASFC $\square$ IGCC

Figure 4. Global comparative assement of different coal life cycles according to theclimate change.

Comparative assessment of different coal life cycle stage according to climate change

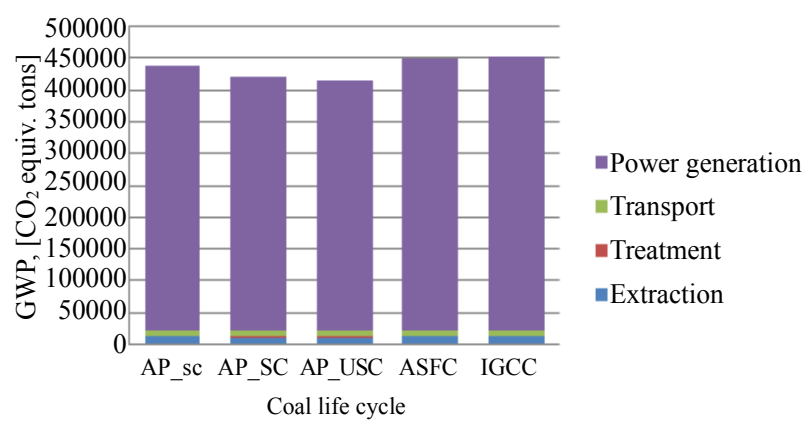

Figure 5. Comparative assessment of different coal life cycle stages according to the climate change.

combustion (ASFC); and integrated gasification combined cycle (IGCC). In addition, the contribution of the coal life cycle stage to the climate is presented. The power generation stage has the highest contribution to the climate change due to the $\mathrm{CO}_{2}$ emissions generated by coal combustion.

Figure 4 presents a comparison of different coal life cycles with the energy conversion stage. The analysis of different ways to produce the electricity from coal shows
Green house gases contribution to climate change

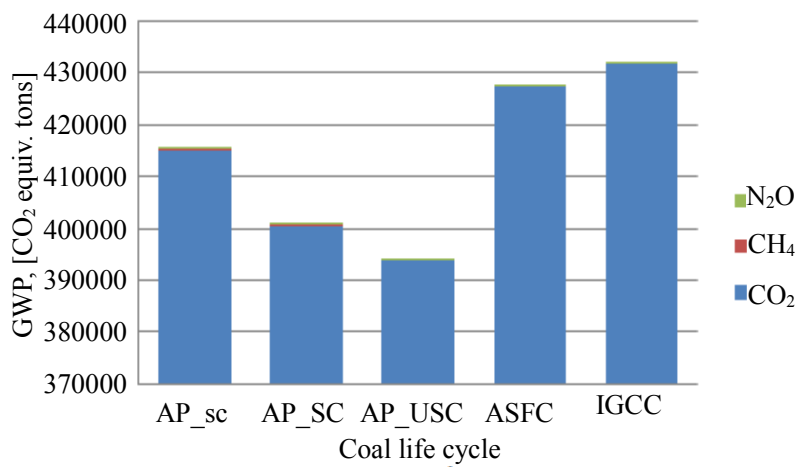

Figure 6. The contribution of green house gases to the climate change power generation stage.

no obvious difference between the GWP impact indicators. But, if we analyze the whole coal life cycle, we notice that the power generation stage has the main contribution to the climate change ( $>95 \%)$ independent of how the energy technology was used.

For the reduction of the environmental impact of the coal life cycle used in the energy sector the integration of the $\mathrm{CO}_{2}$ capture section is necessary. In Figures 7-9 the effects on the eutrophisation class impact is presented for the coal life cycle.

The $\mathrm{NO}_{2}$ and $\mathrm{NH}_{3}$ are the pollutants that have a contribution to the eutrophisation class. However, the $\mathrm{NO}_{2}$ is the main pollutant and it is generated in the power generation stage. The $\mathrm{NH}_{3}$ is generated in the power generation stage as a result of the measures taken to reduce the $\mathrm{NO}_{\mathrm{x}}$ emissions.

Figures 10-12 show the impact of the coal life cycles according to POCP. In this case, the IGCC solution has a small impact due to the $\mathrm{SO}_{\mathrm{x}}$ desulphurization before syngas combustion.

$\mathrm{NO}_{2}$ and $\mathrm{SO}_{2}$ are the pollutants with the main contribution to the POCP. The difference between technologies consists in the measured applied for $\mathrm{SO}_{2}$ emissions reducetion.

The effects on the environment according to human toxicity of the coal life cycle are presented in Figures 13-15. 
Comparative assessment of different coal life cycle according to eutrophisation ( $\mathrm{PO}_{4}^{3-}$ eqiuiv. tons)

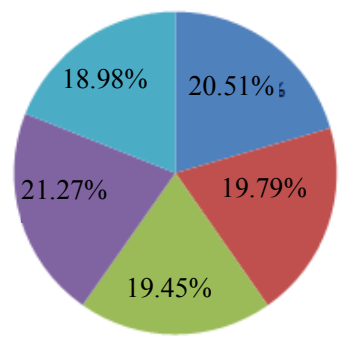

$\backsim \mathrm{AP} \_\mathrm{sc} \backsim \mathrm{AP} \_\mathrm{SC} \backsim \mathrm{AP} \_\mathrm{USC} \backsim \mathrm{ASFC} \backsim \mathrm{IGCC}$

Figure 7. Global comparative assement of different coal life cycles according to the eutrophisation.

Comparative assessment of different coal life cycle stage according to eutrophisation

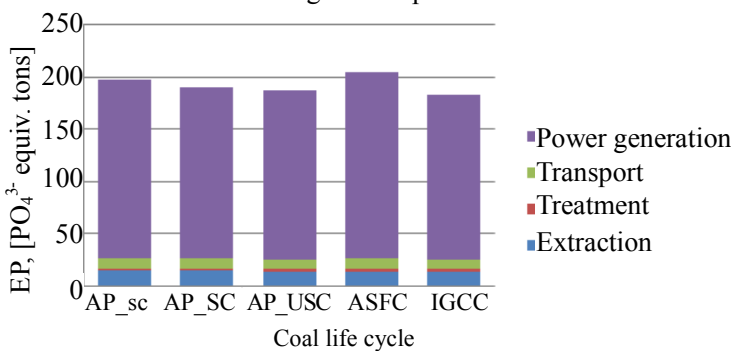

Figure 8. Comparative assessment of different coal life cycle stages according to the eutrophisation.

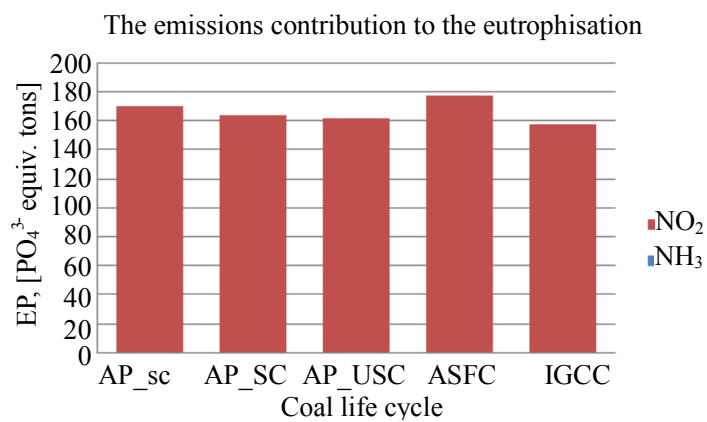

Figure 9. The contribution of the emissions to the eutrophisation.

Comparative assessment of different coal life cycle according to $\mathrm{POCP}\left(\mathrm{C}_{2} \mathrm{H}_{6}\right.$ eqiuiv. tons $)$

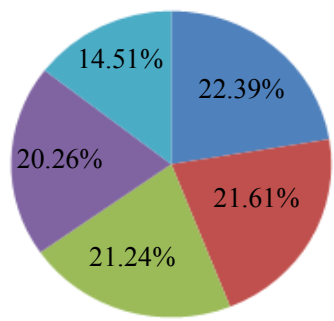

$=\mathrm{AP} \_\mathrm{sc}=\mathrm{AP} \_\mathrm{SC} \equiv \mathrm{AP} \_\mathrm{USC}=\mathrm{ASFC}=\mathrm{IGCC}$

Figure 10. Global comparative assement of different coal life cycle according to POCP.

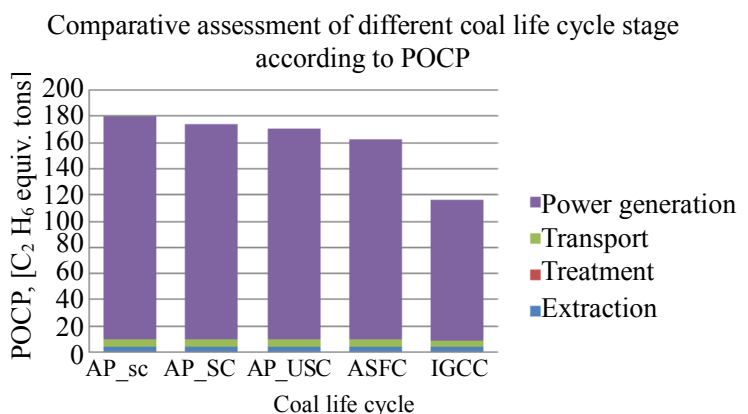

Figure 11. Comparative assessment of different coal life cycle stages according to $\mathrm{POCP}$.

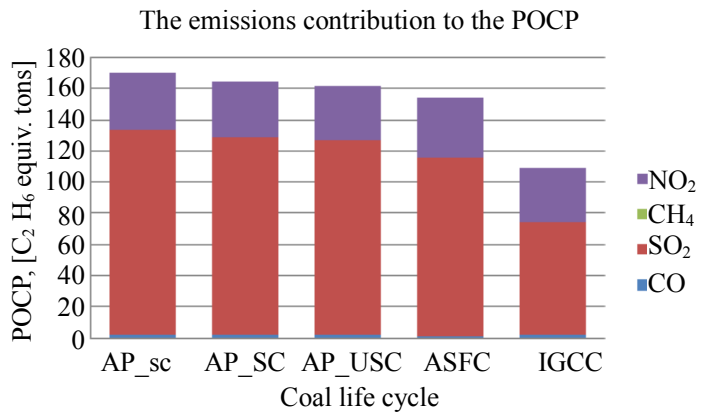

Figure 12. The contribution of the emissions to the POCP.

Comparative assessment of different coal life cycle according to HTP (1,4 DCB eqiuiv. tons)

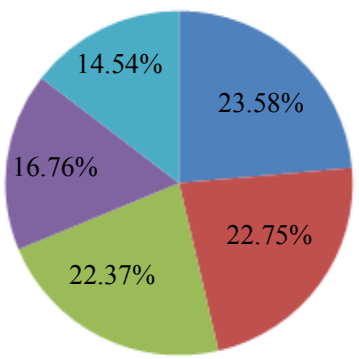

$\approx \mathrm{AP} \_\mathrm{sc} \backsim \mathrm{AP} \_\mathrm{SC} \backsim \mathrm{AP} \_\mathrm{USC} \backsim \mathrm{ASFC} \backsim \mathrm{IGCC}$

Figure 13. Global comparative assement of different coal life cycles according to HTP.

Comparative assessment of different coal life cycle stage according to HTP

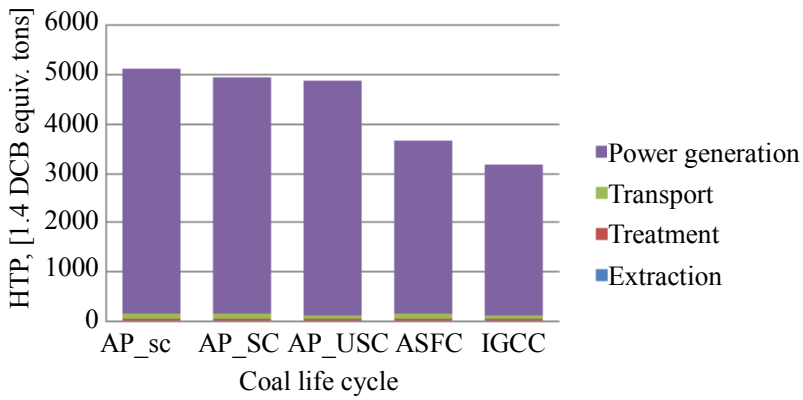

Figure 14. Comparative assessment of different coal life cycle stages according to HTP. 
The IGCC and CFBC technology have a small environmental impact considering HTP compared to pulverized coal combustion.

The pollutants that contribute to the human toxicity class are generated mainly during the power generation stage. The other stages of the coal life cycle are a small contribution to this environmental indicator (less than $2 \%)$.

The main pollutants that contribute to the human toxicity indicator are dust, $\mathrm{NO}_{2}$ and $\mathrm{SO}_{2}$, which are generated mostly in the combustion stage.

Figures 16-18 show the environmental impact of the coal life cycle according to acidification.

Considering the low emissions of $\mathrm{SO}_{2}$ generated in the combustion stage, IGCC have a small environmental impact. In contrast, the pulverized coal has the biggest environmental impact.

As in the POCP case, the $\mathrm{SO}_{2}$ emissions have the main contribution, mainly generated during the power generation stage.

In Figure 19 a comparative assessment between different coal life cycles is presented. In order to produce

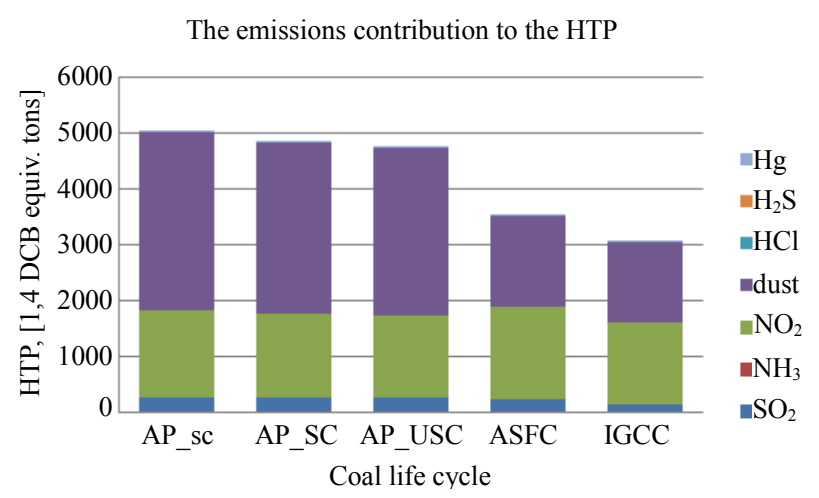

Figure 15. The contribution of the emissions to the HTP.

Comparative assessment of different coal life cycle according to $\mathrm{AP}\left(\mathrm{SO}_{2}\right.$ eqiuiv. tons)

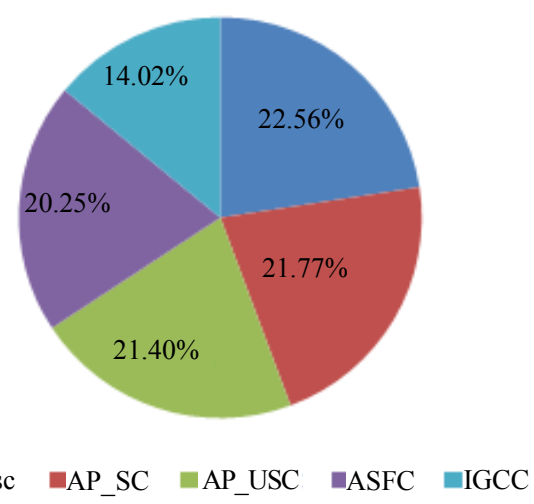

Figure 16. Global comparative assement of different coal life cycles according to AP.

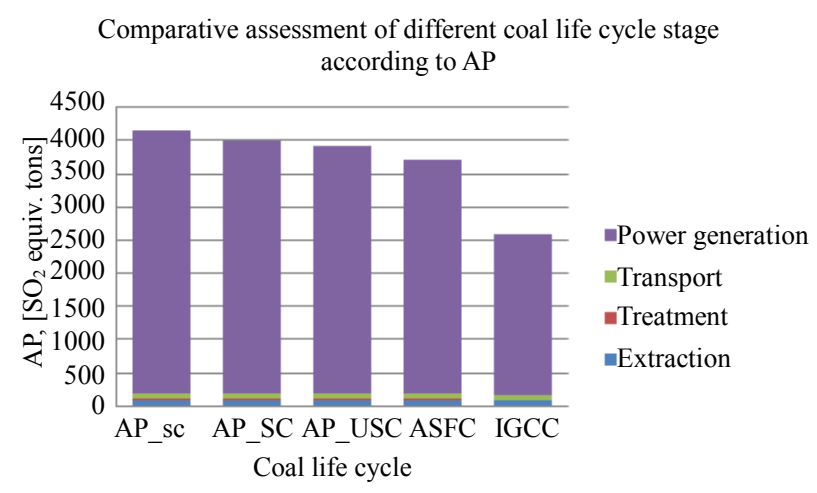

Figure 17. Comparative assessment of different coal life cycle stages according to AP.

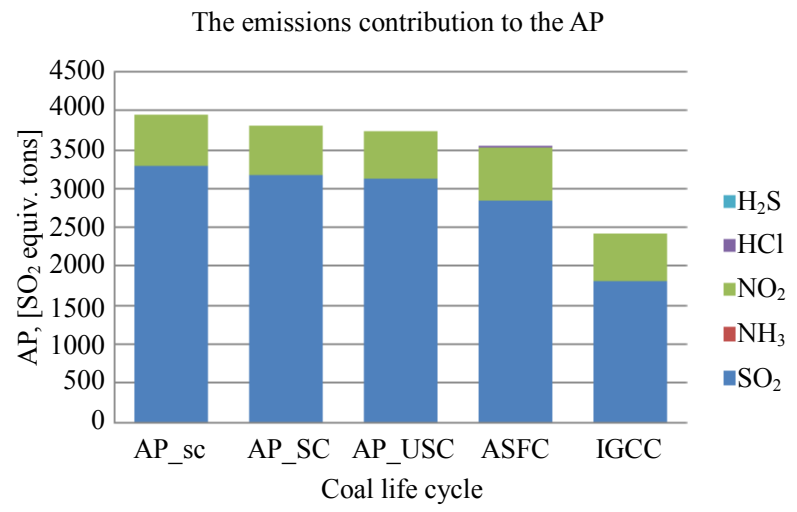

Figure 18. The contribution of the emissions to the AP.

Comparative assessment of different coal life cycle according to $\mathrm{ADP}$ (antimoniu eqiuiv. tons)

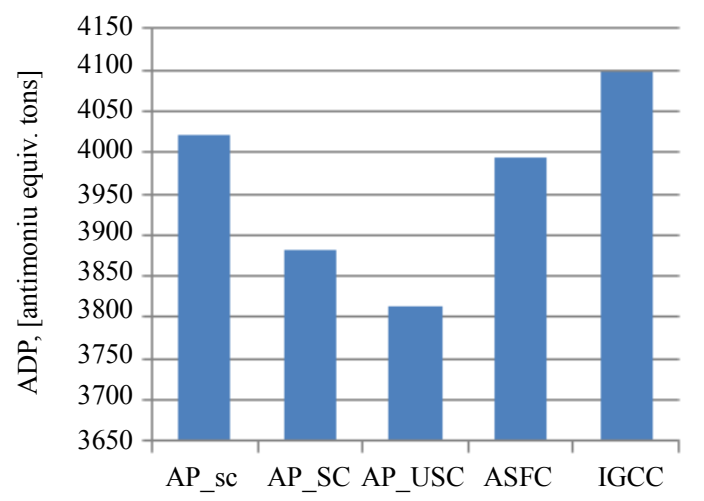

Figure 19. Comparative assement of different coal life cycles according to ADP.

the energy required by the consumer, the pulverized coal combustion with ultra-supra-critical parameters has the lowest amount of coal compared to other technologies.

Therefore, in order to reduce the GHG emissions we propose to integrate the $\mathrm{CO}_{2}$ capture section in the circulating fluidized bed combustion and to analyze the global environmental effects. 


\subsection{Circulating Fluidized Bed Combustion with $\mathrm{CO}_{2}$ Capture}

Figure 20 presents the CFBC pilot installation with $\mathrm{CO}_{2}$ chemical absorption process integration. The $\mathrm{CO}_{2}$ chemical absorption capture process includes an absorber and a stripper unit. In order to increase the $\mathrm{CO}_{2}$ capture performance the following process parameters were optimized in this study: MEA absorption capacity, the thermal energy required for solvent regeneration, and the $\mathrm{CO}_{2}$ capture efficiency. The optimization was performed by varying the lean and rich loading value of solvent. The difference between the last two parameters represents the MEA absorption capacity.

Legend:

(A) - the rich loading solvent after the Absorber unit (measure point);

(B) - the rich loading solvent after the reservoir "MEA rich" (measure point);

(c) - the lean loading solvent after the economizer (measure point);

(D)- the lean loading solvent after the re-boiler unit (measure point);

() - the lean loading solvent after the reservoir "MEA lean" (measure point);

(T) - the temperature measure point;

(1) - the electric current intensity measure point; c.w. - cold water;

1- the gas analyzer (TESTO).

Before entering the absorber unit, the flue gases are desulphurized using $1.5 \% \mathrm{NaOH}$. The absorber unit is realized by a modern packing design using aRaschig ring with a nominal size of $16 \mathrm{~mm}$ [11]. Hence, the absorber column has a number of 8 theoretical stages with the contact surface area of around $120 \mathrm{~m}^{2} / \mathrm{m}^{3}$.

The coal composition was: $\mathrm{C}-21.55 \%$; $\mathrm{H}-1.25 \%$; O $-2.55 \% ; \mathrm{N}-0.65 \% ; \mathrm{S}-1 \%$. For this last analysis of the lignite used, the low heating value $7543 \mathrm{MJ} / \mathrm{kg}$.

Table 3 shows the range of variation for the process parameters analyzed.

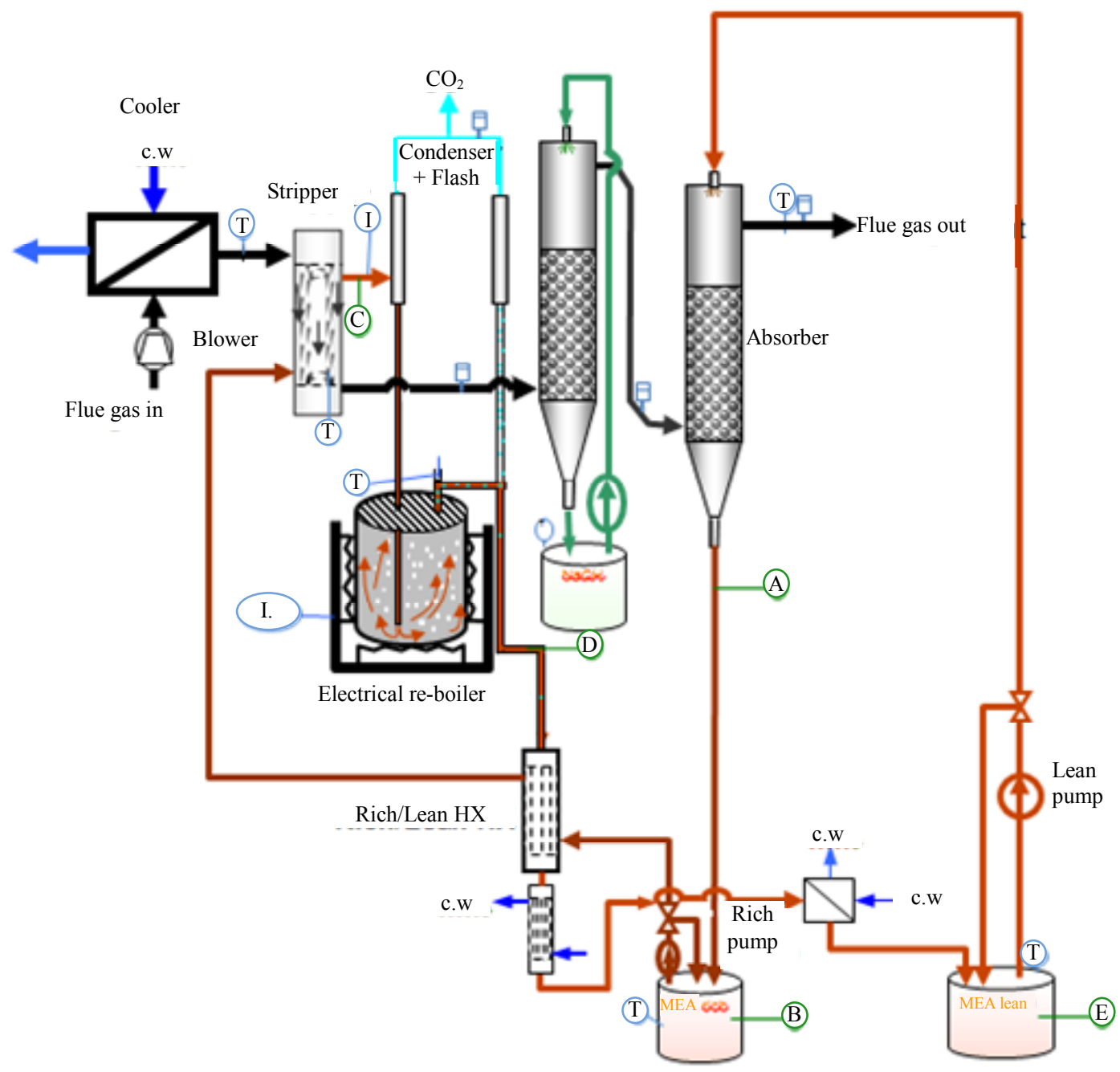

Figure 20. The $\mathrm{CO}_{2}$ post-combustion section. 
Table 3. The range of process parameters.

\begin{tabular}{|c|c|c|}
\hline Process parameter & Range of variation & Process conditions \\
\hline Solvent flow rate, $\mathrm{kg} / \mathrm{h}$ & $500-1800$ & $\mathrm{p}_{\mathrm{abs}}$-ct.; $\varepsilon_{\mathrm{CO}_{2}}$-ct.; $\mathrm{C}_{\mathrm{MEA}}$-ct. \\
\hline $\mathrm{CO}_{2}$ partial pressure, atm & $\sim 0.11$ & n.a. \\
\hline Temperature of absorption, ${ }^{\circ} \mathrm{C}$ & $31-49$ & $\mathrm{p}_{\mathrm{abs}}-\mathrm{ct}$.; $\varepsilon_{\mathrm{CO}_{2}}$-ct.; $\mathrm{C}_{\mathrm{MEA}}$-ct. \\
\hline Pressure of absorption process, atm & $1.1-2.1$ & n.a. \\
\hline $\mathrm{L} / \mathrm{G}$ ratio, $\mathrm{kg}_{/} / \mathrm{kg}_{\mathrm{g}}$ & $0.45-1.62$ & $\mathrm{p}_{\mathrm{abs}}$-ct.; $\varepsilon_{\mathrm{CO}_{2}}$-ct.; $\mathrm{C}_{\mathrm{MEA}}$-ct. \\
\hline $\mathrm{CO}_{2}$ efficiency, $\%$ & $\sim 90$ & $\mathrm{p}_{\mathrm{abs}}$-ct.; $\mathrm{C}_{\mathrm{MEA}}$-ct. \\
\hline MEA concentration, wt. $\%$ & $\sim 25$ & pabs \\
\hline
\end{tabular}

\section{Results and Discussion}

The objective of this paper was to ameliorate the environmental impact on the coal life cycle by reducing the GHG emissions generated during the power generation stage. In this respect, we analyzed the integration of the $\mathrm{CO}_{2}$ post-combustion capture in the circulated fluidized bed combustion. We also, analyzed the effects on the $\mathrm{CO}_{2}$ capture section integration in the power plant on the environmental impact.

Firstly, the MEA capacity was determined by measureing the lean and rich loading solvent in different points indicated in Figure 20 [11]. Thus, Table 4 shows the values determined for the solvent.

As for the absorption capacity of MEA, the results were validated in the similar study $[18,19]$.

Points A, B, C, D, E are indicated in the legend of Figure 20. The difference between points $A$ and $E$ represents the absorption capacity of the MEA for $25 \% \mathrm{wt}$. concentration in the solvent.

Figure 21 shows the variation of the energy required by the solvent according to the $\mathrm{CO}_{2}$ capture efficiency for different $\mathrm{L} / \mathrm{G}$ ratio.

One can notice that for each $\mathrm{L} / \mathrm{G}$ ratio a minimal value of energy required is obtained for $90 \% \mathrm{CO}_{2}$ capture efficiency. The optimal value for $\mathrm{L} / \mathrm{G}$ ratio was $0.7 \mathrm{~kg} / \mathrm{kg}_{\mathrm{g}}$. So, for a flue gas flow (according to coal flow and the excess air) $0.7 \mathrm{~kg}$ of liquid solvent is necessary for a $\mathrm{CO}_{2}$ capture efficiency of $90 \%$. This value for the solvent prevents the metallic surface corrosion by using a higher solvent flow.

Table 5 shows a comparative environmental assessment between a power plant with circulating fluidized bed combustion of coal with and without $\mathrm{CO}_{2}$ capture for supra-critical and ultra-supra-critical parameters.

After the integration of the $\mathrm{CO}_{2}$ capture chemical absorption process in the power plant, and for the same functional unit, the GWP impact indicator decreased from 450,760 to $75,937 \mathrm{CO}_{2}$ equiv. tons and from 438,122 to $73,245 \mathrm{CO}_{2}$ equiv. tons.

But the $\mathrm{CO}_{2}$ capture process integration in the power plant has reduced the power plant global efficiency with almost $6 \%$, which means that more fuel was needed in order to accomplish the functional unit. However, for a good absorption capacity of the MEA solvent, the flue gas was desulphurized which permitted the considerable reduction of the acidification potential indicators.

\section{Conclusions}

In this paper the coal life cycle was investigated from the environmental point of view in order to identify the amount of GHG emissions generated. Three energy solutions (pulverized coal with sub-critical, supra-critical and ultra-supra-critical parameters; circulating fluidized bed combustion and integrated gasification with combined cycle) were analyzed and compared from different indicator impacts. The power generation stage has the main contribution to the environmental impact for all the impact indicators analyzed. As for the GHG emissions, the main pollutant is $\mathrm{CO}_{2}$ for all the energy technologies analyzed. In order to ameliorate the environmental impact of the coal life cycle concerning the GHG emissions, the $\mathrm{CO}_{2}$ capture by chemical absorption was proposed for the integration in the ASFC technology.

In order to capture the $\mathrm{CO}_{2}$ the MEA solvent was used ( $25 \%$ wt. in solvent).The MEA absorption capacity was measured in various points of the experimental installation and the procedure was repeated for data validation. The average MEA absorption capacity was $0.07 \mathrm{~mol}$ $\mathrm{CO}_{2} / \mathrm{mol}$ MEA. The energy required by the process for the regeneration of the MEA solvent was 2.9 and 2.77 $\mathrm{GJ} / \mathrm{tCO}_{2}$ captured in the case of supra-critical and ultra-supra-critical parameters. A steam flow was extracted from the low pressure steam turbine (LPST) in order to regenerate the MEA solvent. An energy penalty was $5.94 \%$ and $6.4 \%$ respectively for both cases.

On the other hand, for the coverage of the functional unit more fuel is needed and in that case one can notice an increase of the abiotic depletion potential with approximately $16 \%$ as compare to the power plant without $\mathrm{CO}_{2}$ capture. In order to reduce the corrosive impact of 
Table 4. Lean and rich loadings at the five points of the pilot installation (25\% MEA), in (mol $\mathrm{CO}_{2} / \mathrm{mol} \mathrm{MEA}^{\mathrm{M}}$.

\begin{tabular}{cccccc}
\hline \multirow{2}{*}{ Sample } & \multicolumn{2}{c}{ Rich loading solvent } & \multicolumn{3}{c}{ Lean loading solvent } \\
\cline { 2 - 6 } & $\mathbf{A}$ & $\mathbf{B}$ & $\mathbf{C}$ & $\mathbf{D}$ & $\mathbf{E}$ \\
\hline 1 & 0.51 & 0.574 & 0.52 & 0.317 & 0.434 \\
2 & 0.506 & 0.568 & 0.518 & 0.325 & 0.429 \\
3 & 0.503 & 0.578 & 0.512 & 0.318 & 0.444 \\
4 & 0.521 & 0.584 & 0.518 & 0.314 & 0.438 \\
5 & 0.517 & 0.569 & 0.517 & 0.324 & 0.432 \\
6 & 0.501 & 0.567 & 0.524 & 0.319 & 0.429 \\
7 & 0.497 & 0.566 & 0.513 & 0.32 & 0.421 \\
8 & 0.489 & 0.571 & 0.509 & 0.317 & 0.43 \\
Average & 0.502 & 0.575 & 0.511 & 0.318 & 0.433 \\
\end{tabular}

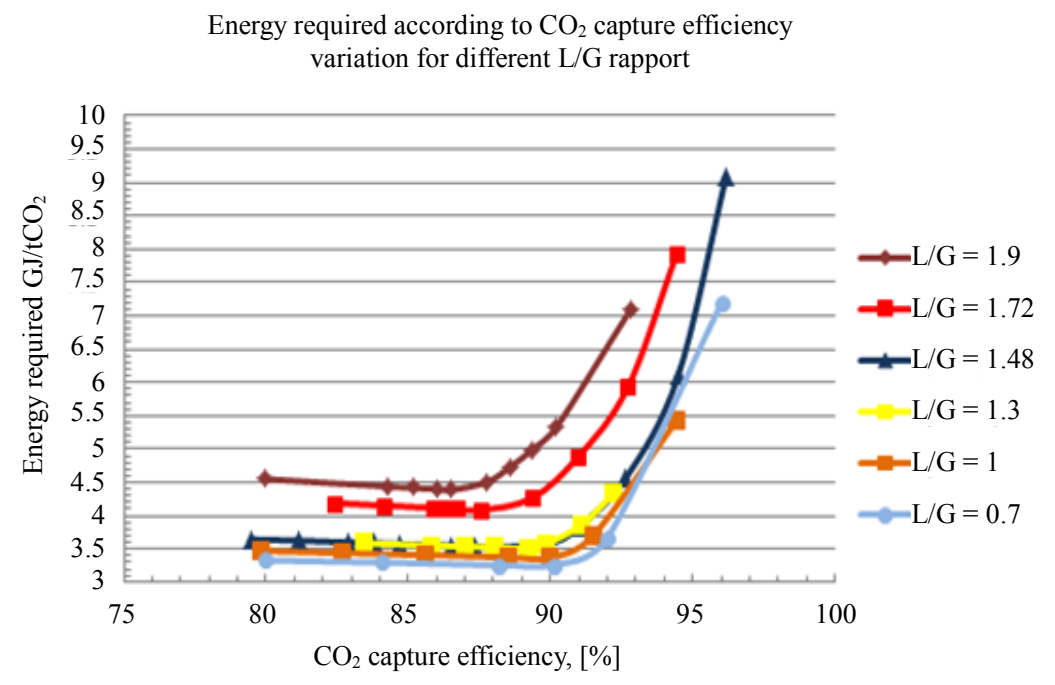

Figure 21. The optimal value of the energy required according to the $\mathrm{CO}_{2}$ capture efficiency and $\mathrm{L} / \mathrm{G}$ rapport.

Table 5. Comparative assessment between the power plants with and without $\mathrm{CO}_{2}$ capture.

\begin{tabular}{|c|c|c|c|c|}
\hline \multirow[t]{2}{*}{ Process Parameter } & \multicolumn{2}{|c|}{ Power plant without $\mathrm{CO}_{2}$ capture } & \multicolumn{2}{|c|}{ Power plant with $\mathrm{CO}_{2}$ capture } \\
\hline & A & B & A & $\mathrm{B}$ \\
\hline \multicolumn{5}{|l|}{ Steam cycle parameters } \\
\hline Functional unit, MWh & 420000 & 420000 & 420000 & 420000 \\
\hline $\mathrm{CO}_{2}$ removal steam generator output, $\mathrm{kW}$ & - & - & 38550 & 39889 \\
\hline Heat consumed for main steam, $\mathrm{kW}$ & 649265 & 623025 & 649265 & 623025 \\
\hline \multicolumn{5}{|l|}{$\mathrm{CO}_{2}$ removal system parameters } \\
\hline MEA solvent concentration, $\%$ & - & - & 25 & 25 \\
\hline Solvent regeneration energy, $\mathrm{GJ} /$ tonne $\mathrm{CO}_{2}$ & - & - & 2.9 & 2.77 \\
\hline Steam flow in the LPST, $\mathrm{kg} / \mathrm{s}$ & 185.02 & 179.04 & 119.89 & 116.02 \\
\hline Steam extraction flow for MEA regeneration, $\mathrm{kg} / \mathrm{s}$ & - & - & 65.13 & 63.02 \\
\hline \multicolumn{5}{|l|}{ Plant performance parameter } \\
\hline Net plant efficiency,\% & 46.21 & 48.15 & 40.27 & 41.75 \\
\hline Energy penalty,\% & - & - & 5.94 & 6.4 \\
\hline \multicolumn{5}{|l|}{ Environment indicator } \\
\hline $\mathrm{ADP}$, antimony equiv. tons & 3994 & 3890 & 4651.6 & 4486.7 \\
\hline GWP, $\mathrm{CO}_{2}$ equiv. tons & 450760 & 438122 & 75937 & 73245 \\
\hline POCP, $\mathrm{C}_{2} \mathrm{H}_{6}$ equiv. tons & 163.18 & 158.61 & 63.48 & 61.23 \\
\hline HTP, 1,4 DCB equiv. tons & 3655.7 & 3553.2 & 3996.1 & 3854.5 \\
\hline $\mathrm{AP}, \mathrm{SO}_{2}$ equiv. tons & 3728.6 & 3624.1 & 1179.3 & 1137.5 \\
\hline $\mathrm{EP}, \mathrm{PO}_{4}^{3-}$ equiv. tons & 205.21 & 199.45 & 238.49 & 230.03 \\
\hline
\end{tabular}


the MEA used, in this study it is obtained an L/G optimal ratio. Thus, a small amount of MEA solvent is used for the same amount of thermal energy used by the process. By tacking in account the $\mathrm{CO}_{2}$ capture efficiency and the minimal value for energy required by the process, the $\mathrm{L} / \mathrm{G}$ optimum was obtained $0.7 \mathrm{~kg}_{\mathrm{l}} / \mathrm{kg}_{\mathrm{fg}}$.

\section{Acknowledgements}

The study has been funded by the UEFISCDI within the National Project number 38/2012 with the title: "Technical-economic and environmental optimization of CCS technologies integration in power plants based on solid fossil fuel and renewable energy sources (biomass)" CARBOTECH.

\section{REFERENCES}

[1] "Statistical Review of World Energy BP," 2010. www.bp.com

[2] E. Tzimas, A. Mercier, C. C. Cormos and S. Peteves, "Trade-Off in Emissions of Acid Gas Pollutants and of Carbon Dioxide from Fossil Fuels Power Plants with Carbon Capture," Energy Policy, Vol. 35, No. 8, 2007, pp. 3991-3998. doi:10.1016/j.enpol.2007.01.027

[3] European Commission, "DG Energy and Transport (TREN), Strategic Energy Review,” 2009. http://ec.europa.eu/energy

[4] "Intergovernmental Panel on Climate Change (IPCC), 4th Assessments Report, Climate Change," 2007. www.ipcc.ch

[5] European Commission, "Strategy on Climate Change: The Way Ahead for 2020 and Beyond," 2007.

[6] "Intergovernmental Panel on Climate Change (IPCC), Special Report, $\mathrm{CO}_{2}$ Capture and Storage," 2005. www.ipcc.ch

[7] J. D. Figueroa, T. Fout, S. Plasynski, H. McIlvired and R. Srivastava, "Advances in $\mathrm{CO}_{2}$ Capture Technology-The U.S. Department of Energy's Carbon Sequestration Program," International Journal of Greenhouse Gas Control, Vol. 2, No. 1, 2008, pp. 9-20. doi:10.1016/S1750-5836(07)00094-1

[8] E. Favre, "Carbon Dioxide Recovery from Post-Combustion Processes: Can Gas Permeation Membranes Compete with Absorption," Journal of Membrane Science, Vol. 294, No. 1-2, 2007, pp. 50-59. doi:10.1016/j.memsci.2007.02.007

[9] E. Favre, R. Bounaceur and D. Roizard, "A Hybrid Process Combining Oxygen Enriched Air Combustion and Membrane Separation for Post Combustion Carbon Dioxide Capture," Separation and Purification Technology, Vol. 68, No. 1, 2009, pp. 30-36.

\section{doi.org/10.1016/j.seppur.2009.04.003}

[10] S. C. Page, A. G. Williamson and I. G. Mason, "Carbon Capture and Storage: Fundamental Thermodynamics and Current Technology," Energy Policy, Vol. 37, No. 9, 2009, pp. 3314-3324. doi:10.1016/j.enpol.2008.10.028

[11] C. Dinca and A. Badea, "The Parameters Optimization for a CFBC Pilot Plant Experimental Study of Post-Combustion $\mathrm{CO}_{2}$ Capture by Reactive Absorption with MEA," International Journal of Greenhouse Gas Control, Vol. 12, 2013, pp. 269-279. doi:10.1016/j.ijggc.2012.11.006

[12] A. Kather and S. Linnenberg, "Evaluation of an Integrated Post-Combustion $\mathrm{CO}_{2}$ Capture Process for Varying Loads in a Coal-Fired Power Plant Using Monoethanolamine," 4th International Conference on Clean Coal Technologies, Dresden, 2009.

[13] J. Husebye, R. Anantharaman and S.-E. Fleten, “Technoeconomic Assessment of Flexible Solvent Regeneration \& Storage for Base Load Coal-Fired Power Generation with Post Combustion $\mathrm{CO}_{2}$ Capture," Energy Procedia, Vol. 4, 2011, pp. 2612-2619. doi:10.1016/j.egypro.2011.02.160

[14] B. A. Oyenekan and G. T. Rochelle, "Energy Performance of Stripper Configurations for $\mathrm{CO}_{2}$ Capture by Aqueous Amine," Industrial \& Engineering Chemistry Research, Vol. 45, No. 8, 2006, pp. 2457-2464. doi:10.1021/ie050548k

[15] M. S. Jassim and G. T. Rochelle, "Innovative Absorber/ Stripper Configurations for $\mathrm{CO}_{2}$ Capture by Aqueous Monoethanolamine," Industrial \& Engineering Chemistry Research, Vol. 45, No. 8, 2006, pp. 2465-2472. doi:10.1021/ie050547s

[16] A. Lawal, M. Wang, P. Stephenson and O. Obi, "Demonstrating Full-Scale Post-Combustion $\mathrm{CO}_{2}$ Capture for Coal-Fired Power Plants through Dynamic Modelling and Simulation," Fuel, Vol. 101, 2012, pp. 115-128. doi:10.1016/j.fuel.2010.10.056

[17] C. Dinca, A. Badea, et al., "A Multi-Criteria Approach to Evaluate the Natural Gas Energy Systems," Energy Policy, Vol. 35, No. 11, 2007, pp. 5754-5765, doi:10.1016/j.enpol.2007.06.024

[18] L. Simon, E. Yannick, P. Graeme, Y. Artanto and K. Hungerbuhler, "Rate Based Modeling and Validation of a Carbon-Dioxide Pilot Plant Absorption Column Operating on Monoethanolamine," Chemical Engineering Research and Design, Vol. 89, No. 9, 2011, pp. 1684-1692. doi:10.1016/j.cherd.2010.10.024

[19] Y. Zhang, H. Chen, C. Chen, J. M. Plaza, R. Dugas and G. T. Rochelle, "Rate-Based Process Modeling Study of $\mathrm{CO}_{2}$ Capture with Aqueous Mono-Ethanolamine Solution," Industrial \& Engineering Chemistry Research, Vol. 48, No. 20, 2009, pp. 9233-9246. doi:10.1021/ie900068k 